\title{
Social Security and robotization: Possible ways to finance human reskilling and promote employment
}

https://doi.org/10.1515/pjbr-2020-0020

received March 25, 2020; accepted May 20, 2020

\begin{abstract}
This contribution aims to open the discussion on how to balance the opportunities and the risks posed by the increased robotization of the economy. It particularly addresses the concerns related to the sustainability of the current Social Security systems. Having in mind the quick process of skill depreciation, it is urgent to incentivize workers' training and human employment. Some ways already used in the past to finance similar goals are reviewed here in order to show possible solutions to be adapted in the near future within the European Union in line with the guidelines given by several international institutions.
\end{abstract}

Keywords: robotization, social security, reskilling, training and employment incentives

\section{Introduction}

This article provides an overview of the current situation of unstoppable progress in the implementation of robots in different domains. Additionally, it points out the limitations that the contemporary Social Security systems face in order to subsist, which are derived from certain technical choices that affect their design. Methodologically, several useful data available at a global, regional and national level are used to illustrate these phenomena. ${ }^{1}$

The research conducted makes an attempt to answer the following question: Is it possible to find a win-win scenario, where human-centered gains can be obtained, benefitting both companies and society as a whole through incentivizing workers' reskilling and hence their employability?

The contents are structured as follows: the next section highlights some risks and opportunities brought by robotization to the labor market. It also describes the core problem affecting the sustainability of the Social Security systems: the imbalance between revenues and expenses. Then the following section explores some existing incentives for training and employment and defends that they could be adapted, in the context of a robotized economy, as possible solutions to try to diminish the unemployment problem and, consequently, to sustain the Social Security system. Finally, the adoption of a consensual European Union (EU) wide response, while coordinating the changes to the national legislations accordingly, is urged as the main conclusion.

\section{The technological progress and the sustainability of Social Security systems: How to balance opportunities and risks?}

\subsection{Conceptual and EU framework}

"A strong robotics industry is key to Europe's future competitiveness. The growth of our robotics industry will generate new jobs and strengthen the European manufacturing sector."2 This statement made in 2012 is still valid.

1 The national description will be focused on Spain, because of the authors' expertise in their country of origin. They encourage foreign colleagues with knowledge in both fields addressed here to develop further comparative studies in other member states of the European Union.

2 In 2012, Neelie Kroes, Vice President of the European Commission responsible for the digital agenda said these words [1].

\footnotetext{
* Corresponding author: María Amparo Grau Ruiz, Full Professor of Financial and Tax Law, Universidad Complutense de Madrid, Madrid, Spain; Visiting Professor of Transnational Taxation, Northwestern University, Chicago, Illinois, USA, e-mail: grauruiz@ucm.es

Alfredo Díaz: Member of the Financial Coordination Advisory Board, Sub-directorate General for Certification and Payments, European Funds Directorate-General, Ministry of Finance, Madrid, Spain
} 
However, keeping up the technological pace also entails some risks. Certain public policy measures can contribute to maximize the positive impacts of robotics and minimize its negative ones. With that purpose in mind, we address which ones could be modified and/or adopted, paying special attention to the Social Security context.

The International Organization for Standardization in ISO 8373/2012, standard on robots and robotic devices, defines the intelligent robot as "a robot capable of performing tasks by probing its environment and/or interacting with external sources and adapting its behaviour." As Nathalie Nevejans [2] indicates, it has a series of fundamental characteristics: it is a physical machine, powered by energy, with the capacity to act in the real-world and analyze its surroundings, which has the ability to learn from these actions and make decisions. ${ }^{3}$ According to ISO 8373, an industrial robot is a multipurpose manipulator that can be programmed automatically and freely, fixed or mobile for use in automation technology, whose main purpose is to increase productivity as well as relieve the burden of tedious or insecure activities that man assumes. On the contrary, the service robot, since the revision of this ISO standard in 2012, is the one that performs useful tasks for people, society or institutions, without intervening in automated industrial production processes.

Europe in 2012 had a quarter of the world production of industrial robotics and a 50\% share in personal and professional services robotics. The forecasts for 2020 were that service robotics could reach a market volume of more than 100,000 million euros a year, which is why the European Commission, industry and academia agreed to launch a partnership between the public sector and the private sector in the field of robotics. ${ }^{4}$ More than two thirds of the EU citizens (70\%) then had a positive opinion of robots: they mostly agreed that robots "are necessary because they do jobs that are too hard or too dangerous for people" $(88 \%)$

3 A lively discussion of the concept of robots by experts can be found in the INBOTS documentary video [3].

4 Its objectives are:

1. Develop strategic objectives for European robotics and promote their realization;

2. Improve the industrial competitiveness of Europe through innovative robotics technologies;

3. Provide robotics products and services as key instruments to help respond to challenges of the European society;

4. Strengthen the integration into networks of the European robotics community;

5. Promote European robotics;

6. Reach new and existing users and markets;

7. Contribute to policy development and address ethical, legal and social issues. and that "they are a good thing for society because they help people" (76\%) [4].

\subsection{The rising demand for robots worldwide}

Let us remark the historical evolution during the last decade. According to the International Federation of Robotics (IFR): "since 2010, demand for industrial robots has risen considerably due to the ongoing trend toward automation and continued technical innovations in industrial robots. From 2013 to 2018, annual installations increased by 19\% on average per year (CAGR). Between 2005 and 2008, the average annual number of robots sold was about 115,000 units, before the global economic and financial crisis caused robot installations to fall to just 60,000 units in 2009 with lots of investments being postponed. In 2010, investments made leeway and drove robot installations to 120,000 units. Until 2015, annual installations had more than doubled to almost 254,000 units. In 2016, the mark of 300,000 installations per year was crossed; and in 2017, installations surged to almost 400,000 units." ${ }^{5}$ The year 2018 was another record year: for the first time over 400,000 units were installed. The forecast was made by IFR for 2019-2022 regarding the worldwide annual sales of industrial robots: 2019: 420,870 units, $\pm 0 \%$ compared to 2018 ; 2022: 583,520 units, $+12 \%$ per year on average from 2020 to 2022 (Figure 1).

The total number of professional service robots sold in 2018 rose by $61 \%$, i.e., to more than 271,000 units, up from roughly 168,000 in 2017 . The sales value increased by $32 \%$ to US $\$ 9.2$ billion. The total number of service robots for personal and domestic use increased by 59\% to about 16.3 million units in 2018. The value was up $15 \%$ to US $\$ 3.66$ billion $[7,8]$. The data provided by IFR are reproduced in Table 1.

\subsection{Toward the transformation of the labor market}

Robotization is quite rapidly impacting the job market. By focusing on the way this market might change, some solutions could be articulated to ensure socially responsible robotization processes $[9,10]$.

5 In 2018, global robot installations increased by $6 \%$ to 422,271 units, worth US\$ 16.5 billion (without software and peripherals). The operational stock of robots was computed at 2,439,543 units $(+15 \%)[5,6]$. 
Table 1: The rising demand for robots worldwide

\begin{tabular}{lll}
\hline \multicolumn{2}{l}{ Professional service robots } \\
\hline 2018 & 271.000 units & $+61 \%$ \\
2019 & 361.000 units & $+33 \%$ \\
2020 & 495.500 units & $+41 \%$ \\
2021 & 700.100 units & $+41 \%$ \\
2022 & 1.019 .300 units & $+41 \%$ \\
\hline Service robots for domestic/household tasks & \\
\hline 2018 & 16.3 million units & $+59 \%$ \\
2019 & 22.1 million units & $+35 \%$ \\
2020 & 30.4 million units & +40 \\
2021 & 42.7 million units & +40 \\
2022 & 61.1 million units & $+40 \%$ \\
\hline
\end{tabular}

Service robots for entertainment

\begin{tabular}{lll}
\hline 2018 & 4.1 million units & $+8 \%$ \\
2019 & 4.5 million units & $+10 \%$ \\
2020 & 4.9 million units & $+10 \%$ \\
2021 & 5.4 million units & $+10 \%$ \\
2022 & 5.9 million units & $+10 \%$ \\
\hline
\end{tabular}

For the International Labour Organization (ILO), technology, demography, globalization and climate change are among the main drivers of changes in the world of work. One should try to understand how they will affect work and society, and what is the best way to take advantage of them to generate opportunities. Technological change is an essential factor of growth and development, although it is also associated with the change in the labor market. The new technological innovations that underpin the fourth industrial revolution, such as big data, three-dimensional printing, artificial intelligence and robotics, to name a few, are having a transformative impact on the nature of work. For example, the distribution of robots is mostly concentrated in the manufacturing sector $(80 \%)$ and in developed
$2011 \square 2015$

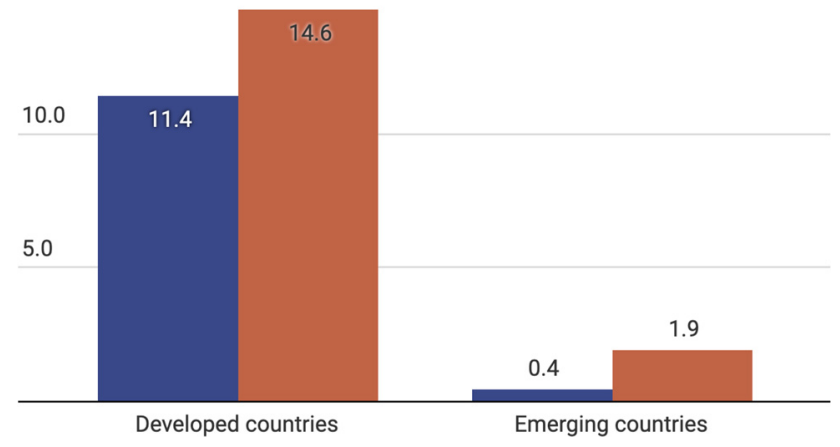

Figure 2: Number of multipurpose industrial robots per 1,000 people employed in the manufacturing sector), ILO, 2016 [11].

countries (80\%). The density of robots, which is measured as the number of industrial robots per thousand people employed in the sector, ranges between 14 in developing countries and 2 in emerging countries [11]. While the main data related to technological developments in the past suggest that the waves of technological changes lead to the destruction of short-term jobs, followed by the creation of new and better jobs, today's technological advances arise at a pace never seen and are causing unprecedented changes in the world. They are often affecting in a diverse way the different countries, as a result of their uneven situations (Figure 2).

\subsection{New and lost jobs}

The jobs, lost and won, related to each of the skills, will vary for each country. Many countries will be able to offer more new jobs than the ones that will disappear. Automation (robots and artificial intelligence) may not have a negative

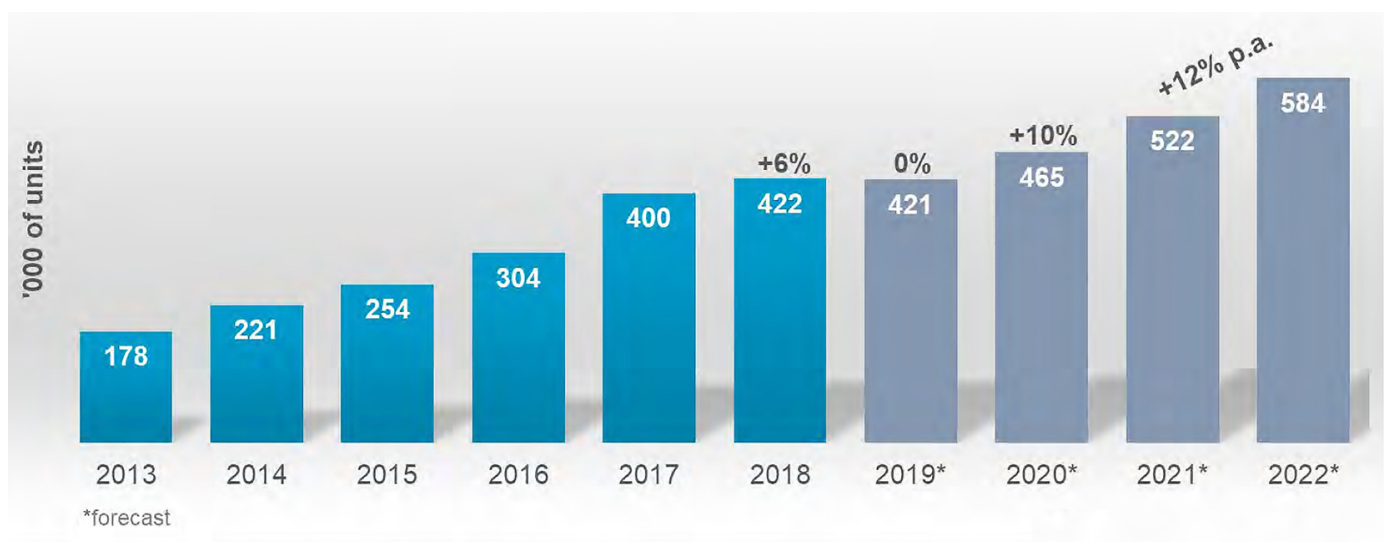

Figure 1: Annual installations of industrial robots $2013-2018$ and $2019^{*}-2020^{*}$, IFR [6]. 


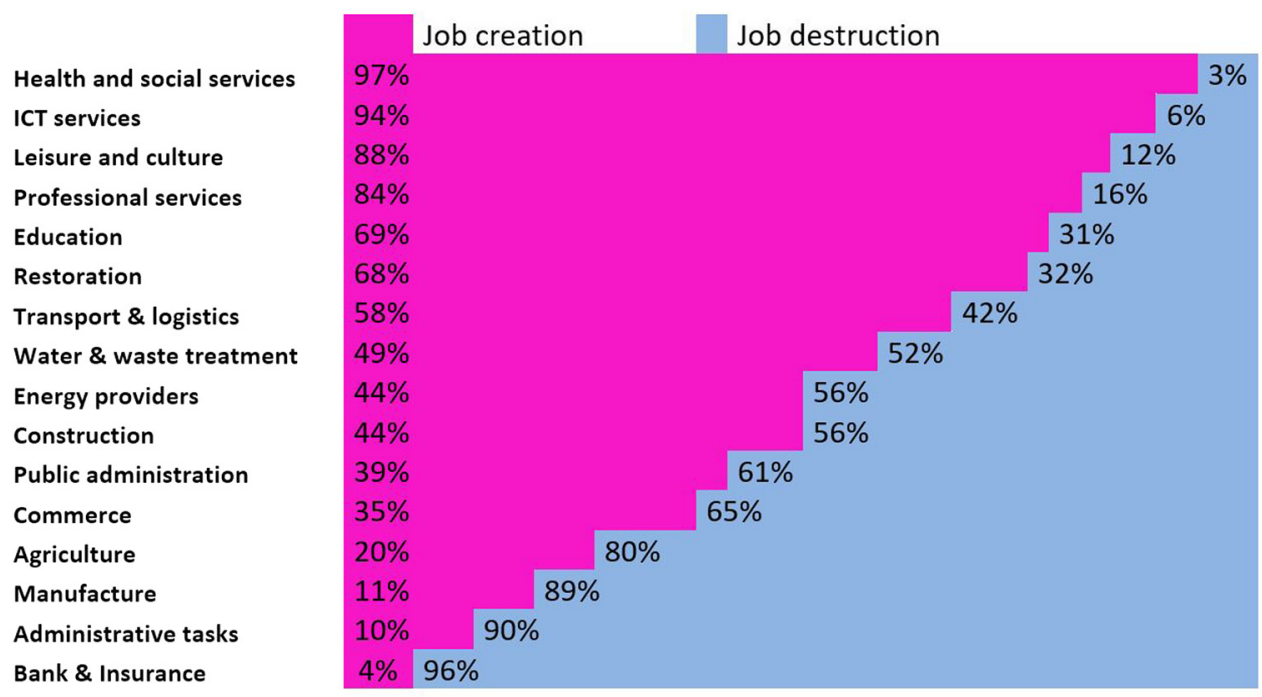

Figure 3: Job creation and destruction in different sectors, 2018 Questionnaire New technologies and the future of work [15].

impact on jobs. Will the countries have workers with the skills required for the new jobs? The fact that new jobs will be created does not necessarily mean that this, alone, will solve the unemployment problem created by the loss of jobs, due to the lack of the required skills. Several public and private organizations are studying the types of skills that will be needed $[12,13]$.

The countries that are able to train their workers in the new skills and retain talented workers can shorten the technological transition period. This will enable them to become more competitive and take advantage of the automation benefits [14].

This should not imply that human reskilling is directed at serving the productivity of robots (machines). On the contrary, let us emphasize the Resolution of the European Parliament of February 16, 2017, on the general principles related to the development of robotics and artificial intelligence for civil use. It points out that they should be aimed at complementing human capabilities and not replacing them. It is essential that human beings maintain control at all times, both in the development process and later in their performance (Figure 3).

\subsection{A look at the Spanish example}

How robotization will affect job creation or destruction may differ from one country to another; however, for a mere illustrative purpose, we are including a recent eloquent graph on the Spanish situation. In Spain, the most favorable sectors for job creation on a 2025 horizon are, by order: health and social services, information and communication technology services, leisure and culture, professional services, education and hospitality restoration. The most disadvantaged will be banking and insurance, administrative tasks, manufacturing, agriculture, commerce and public administration. Technology will contribute to the creation of jobs in areas such as health and social services, leisure, culture, catering, hospitality and transport and logistics. ${ }^{6}$

When profiting from the competitive advantages that advances in new technologies imply, one should counteract the negative effects they may directly generate on employment and indirectly on the financial resources of the Social Security system as well. This affects not only its income/ revenues (by decreasing the ones received through contributions) but also its expense side (by increasing benefits and pensions as a direct consequence of the new situation).

\subsection{The impact on Social Security systems}

The sustainability of the Social Security system is related to the budgetary and financial balance between income/ revenues and expenses (seen from the perspective of this system). That is, the relationship between workers/

6 Information is based on a questionnaire sent to Spanish employers, by Ramón Alós, Professor of Sociology at the Autonomous University of Barcelona. In addition to job creation and destruction, the use of intelligent robots may lead to less working hours. In this sense, billionaire Jack Ma, at the 2019 World Conference on Artificial Intelligence held in Shanghai, argued that people will be able to work 4 hours for 3 days a week, with the help of technological advances and a reform in educational systems. 
taxpayers and pensioners/beneficiaries. Obviously, this equilibrium may be affected by variations in either of these two magnitudes, or both, as happens in situations of either economic or financial crisis, or when economic growth is slow. At low levels of employment, an increase in the volume of expenses of the system (increase in the number as well as the amount of pensions, benefits or subsidies) can coincide with a reduction in income/ revenues as a result of the fall in employment, but also of the lower amount collected as a result of the recognition, for different fair reasons, of bonus.

In the pay-as-you-go pension systems (i.e., current active generation pays the pensions of the current retired one), such as the Spanish Social Security, the drop in employment has a truly important effect. This does not mean that something similar happens in the capitalization systems (i.e., where a periodic payment will result in a capital sum), but, above all, these systems are affected by the fall in the returns on the values of the assets in which the pension plans are invested. ${ }^{7}$

However, in the search for a stable balance, the first option, in order to maintain the solvency of the system, is to control expenses, specifically pensions and benefits. However, the European position does not follow that path, but rather the maintenance of adequate retirement pensions. The foundation is that they constitute the main source of income for older Europeans who, in turn, are an important part of the population of the EU (120 million/ $24 \%$ ). In fact, the basic objective of pension systems for the European Commission is to provide adequate retirement income and allow older people to enjoy a decent standard of living and enjoy economic independence, beyond the important role of automatic stabilizer that it plays. This has been observed during the last economic crisis suffered in which the role of pensioners has been very important: in many cases they have been the only source of resources for families, contributing, in this way, to cope with those hard years. For these reasons, the Thematic Report of the European Semester Adaptation and Sustainability of Pensions also points out that recent reforms of public pensions have tended to improve or maintain the level of protection against poverty.

Another option is to act via income/revenues. That is, it would be necessary to achieve an increase in sufficient levels at least to balance the expenses. The outlook is not hopeful, since despite the undeniable advantages that new technologies produce, such as robotics and artificial intelligence, the

7 On EU Social Security coordination and the room left to each system's configuration by national legislation [16]. important effects they cause on employment cannot be ignored, generating a genuine transformation of the labor market.

The European Parliament in the aforementioned Resolution of February 16, 2017, with recommendations to the Commission on civil law standards on robotics, recalls that during the last two hundred years the employment rate has increased continuously thanks to technological development. It acknowledges that the development of robotics and artificial intelligence has the potential to transform the way of life and ways of working, increase levels of efficiency, savings and security and improve the quality of services, and hopes that, in the short-term and in the medium-term, robotics and artificial intelligence bring efficiency and savings. In particular, the Parliament asked the European Commission to carry out the analysis and supervision of the evolution, in the medium- and long-term, of employment as a result of the development and implementation of robotics and artificial intelligence as well as of the possible scenarios and their consequences on the viability of the Social Security systems of the member states. ${ }^{8}$ The High-Level Expert Group on the Impact of the Digital Transformation on EU Labor Markets in 2019 has partially addressed the necessary Social Security systems' adaptation in the member states of the EU. ${ }^{9}$

As mentioned in the Reflection Document on the Globalization of the EU [21], automation causes labor costs to lose relevance in decisions about where to locate production, so it can contribute to a partial return to Europe of the manufacturing industry, as the European Reshoring Monitor has observed. However, the losses may be greater than the possible recovery that this return brings, as the cost of labor is not a fundamental factor. Thus, from the point of view of the sustainability of the pension system, the problem would persist.

According to the European Reshoring Monitor database, the data on Spanish companies, reported in the national media between January 2014 and December 2019, are provided in Table 2 .

According to the White Pension Book of the EU (2012), the sustainability and adequacy of pension systems depend on the extent to which they can rest on contributions, taxes and savings from working people. To cope with demographic

8 In a similar line, on legal, ethical and socioeconomic aspects of interactive robotics, see the preliminary report of the INBOTS project $[17,18]$. 9 "New and non-standard working arrangements complicate the collection of taxes and social security contributions. In the worst case this could undermine the financial basis of the European social model. But if handled correctly, digitisation could have the opposite effect, reducing compliance costs and increasing collection coverage [19,20]." 
change and the sustainability of public finances, financing agreements, eligibility criteria and labor market conditions would have to be calibrated, so that a balanced relationship between contributions and rights could be established (as between the number of active taxpayers and the number of retired beneficiaries). It is interesting to highlight how those same criteria ("globality" and "integration") that led to establishing strategies to address them could be applied again today to solve the problems derived from robotization.

Likewise, in the Working Paper of the services of the European Commission entitled Report on Spain 2019 [23], it is stated, in relation to the risks of the sustainability of public finances, that the forecast that the public debt will decrease in the period 2018-2020 has not been successful and that the levels of taxation are low compared to expenses. In addition, this report underlines the inadequacy of qualifications and the deficit of skilled labor as another important obstacle to the development and use of advanced technologies. ${ }^{10}$

Having analyzed the situation in a global way and with an eye toward the objectives set by the EU to promote technological development and simultaneously solve the problem of the financial sustainability of Social Security systems, we consider a series of measures aimed at promoting employment in terms of training that could be adapted to the new demand and its financing.

\section{The use of incentives for training and employment as a possible solution (a review of the Spanish experience)}

As previously explained, the sustainability of the Social Security systems could be protected through the control

10 The proposals in the EU for the reform of the pension systems, based on the Annual Prospective Growth Studies in 2017 and 2018 of the Commission, emphasized the importance of ensuring an adequate balance between the years of life labor and retirement years as well as incentivizing complementary private retirement savings plans. For this reason, the recommendations of the Commission were in the following direction: (a) linking the retirement age to increases in life expectancy; (b) restricting access to early retirement plans and other early exit routes from the labor market; (c) favoring the prolongation of working life by facilitating access to lifelong learning, adapting workplaces to a more diversified workforce, developing employment opportunities for older workers and promoting active aging and health; (d) matching the retirement age of men and women; and (e) encouraging the creation of complementary private savings plans to improve retirement income. 
of expenses or the increase in income/revenues. In this section, we will point out some "extraordinary" and "ordinary" ways to act via the latter.

\subsection{Some measures from the income/ revenue side}

To address the imbalance in the Social Security system, the new theoretical possibility of taxing the robots or, where appropriate, their productivity to bear the costs has been considered by several authors [24-28]. In such a case, the problem is whether a robot (machine) can be considered from a legal point of view as a subject of rights and obligations and, therefore, a taxable person obligated to contribute, like any other worker, or taxpayer, either in a personal tax in the case of attribution of income for its contribution to the production process or for the profitability generated by its activity to the entrepreneur. Such profitability would comprise not only by the increase in the productive capacity but also by the savings in personnel costs derived from the activity of the robots.

There could be an extraordinary way to obtain income/ revenues, whose analysis should not be overlooked. It is the portfolio in which the Spanish Social Security Reserve Fund is invested (if that type of reserve exists in a given system). The Consolidated Text of the General Law of Social Security, in Chapter VII of its Title I, currently regulates this Reserve Fund in Spain. ${ }^{11}$ If necessary, it could serve as a minimum protection network. However, the amount available in the Reserve Fund depends on the system's superavit.

\subsection{The hidden potential in some ordinary incentives}

Some of the proposed measures to increase income could discourage and hinder technological innovation, and this risk is to be avoided [29]. Other "ordinary" measures could be adopted in the current transition phase. Tax incentives are both part of the expenses and the income option. From the Social Security perspective, they might imply additional expenses in the present with the possibility for some positive outcomes in the medium- or long-term. The collection of some income/revenues will be thus sacrificed and will not feed the public budget, since those incentives

11 Article 118 of RD Leg 8/2015, of October 30, approves the Consolidated Text of the General Law of Social Security. will be designed to achieve other constitutionally protected goals [30].

In the following pages, we have selected some traditional incentives in the Spanish legal order that allow reductions in the contributions that are due to the Social Security system as they keep a connection with educational needs or transitional inability for other causes. We think that their analysis could serve, as a starting point, to briefly share their basic configuration features and discover the potential to redefine or adapt any of them in the robotization context. ${ }^{12}$ Building a common pool of the existing incentives with this purpose in mind could open possible ways forward to better coordinate Social Security systems in the EU, at this stage where their characteristics are determined by the member states.

The foreseeable loss of some jobs will probably lead to an increase in public expenditures (due to the subsequent needs to finance unemployment benefits or early retirements). Given the impact on the sustainability of the system, one should try to keep active as many people as possible. For that reasons, the availability of true opportunities for reeducation is critical.

In the framework of the Davos 2019 report [31], Guy Ryder, Director General of the ILO, pointed out the need to return people to the center of employment policies. In the current transformative context, it is necessary to consider the right to access to continuing education as an extension of the right to education as well as to invest in policies that allow combining professional experience with education to facilitate the training of workers throughout their professional life. This proposal, as evidenced by data from the survey conducted by the World Economic Forum, would help meet the needs of companies (Figure 4).

In a robotization process the maintenance of jobs by employers via "training incentives" can be encouraged, so that workers can acquire the necessary qualifications in order to get new jobs. Also, via "employment incentives," the employer could be motivated to maintain a job because of favorable factors (the incentive itself and the contribution that the worker could make to the improvement of production) that compensate the salary cost and quote. From the point of view of public spending, in terms of savings, one would have to think not only of the cost of

12 It is important to be aware of the limitations in this analysis due to the lack of a historical series that would allow us to assess the impact of the implementation of robotics and new technologies, their effects on employment as well as the effects of the incentive measures. A statistical evaluation would require a sufficiently broad and refined series to assess the impact that the incentives may have in order to counteract the effects of robotization. 


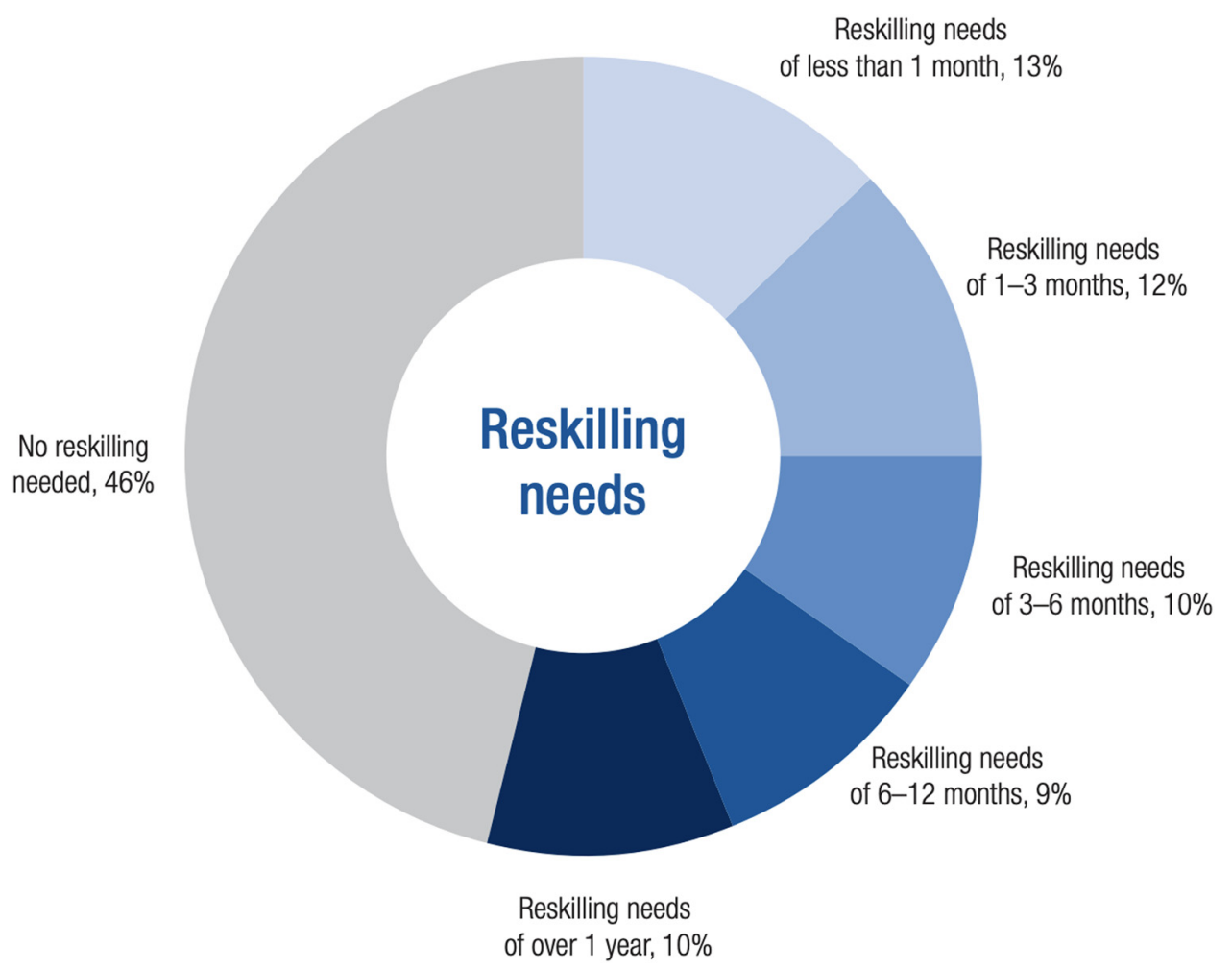

Figure 4: Expected average reskilling needs across companies by share of employees between 2018 and 2022, World Economic Forum, 2018 [31].

the incentive but also of the difference that is not spent for each job that is saved.

\subsubsection{Training incentives}

In the EU, the training and updating of workers, and the financing of this cost have been a concern in the social and labor field since the 1990s. In Spain, the first regulatory frameworks for training in the professional field are found in the National Continuous Training Agreements signed by businessmen, trade unions and the government. Royal Decree 395/2007 already highlighted the key value of the human factor in the global economy and considered the training of workers as a strategic objective to strengthen the productivity and competitiveness of companies and to enhance the employability of workers in a constantly changing world. These criteria were set in line with the objective of the EU for the promotion of employment, where lifelong learning still is an essential part. ${ }^{13}$

13 A good example of this is the incorporation of "lifelong learning or training" among the structural indicators of the Lisbon Strategy for education and training objectives in 2010. The European Council in June 2005 approved the integrated guidelines for growth and employment 2005-2008, including the one aimed at adapting education and training systems to new skills needs.
The Spanish Act 30/2015 emphasized the importance of training worldwide, bringing up what was included in the Organization for Economic Cooperation and Development (OECD) Competition Strategy for 2015 [12]:

The competences have become the international currency of the 21st century economies: in a global society, based more and more on knowledge, it is necessary to invest in training and update it according to the constant evolution of labor market requirements. Achieving better results requires analyzing the skills profile of workers, as well as determining and anticipating the skills required in the market, to develop them, thereby creating better employment and economic development opportunities.

Nowadays, it is clearly admitted: "the tax system could be used to encourage greater private investment in the field of competencies, to encourage companies to hire and encourage all people to offer their skills to the labor market." In short, "greater effort is needed to ensure that labor market regulation and tax policies translate into incentives, not disincentives, to hiring [12,32]." In a competitive environment, with increasing requirements for qualification of workers, the "training incentives" should facilitate the maintenance, access and return to employment.

The Spanish Act 3/2012 established reductions in Social Security contributions for training and learning. The contracts were aimed at the professional qualification of workers 
in a regime of alternation of paid work activity in a company with the training activity received under the vocational training system for employment or the education system. Specifically, during the term of the contract, including extensions, the right to the reduction of corporate contributions to Social Security for common contingencies was recognized as well as those corresponding to accidents at work and occupational diseases, unemployment, salary guarantee fund and professional training, corresponding to these contracts. The amounts varied: $100 \%$ if the contract was made by companies whose workforce was less than 250 people or $75 \%$ when the contracting company had a workforce equal to or greater than that figure. In addition, there was also a $100 \%$ reduction in workers' contributions to Social Security during the entire term of the contract, including extensions. ${ }^{14}$

The Spanish Act 30/2015 linked the vocational training system for employment in the workplace with three distinct ways of financing:

- On the one hand, the funds from the "professional training fees" are key. Both the company and the workers contribute in accordance with the provisions of the State Budgetary Law for each fiscal year. In 2019, the business and workers' support to training is $0.70 \%$ of the contribution base, of which $0.60 \%$ corresponds to the company and $0.10 \%$ to the worker.

- On the other hand, training activities are also financed with the specific contributions established in the State Public Employment Service budget, and with the own funds that the Autonomous Communities can allocate in the exercise of their competence. Co-financing through the European Social Fund or other European aid is also possible. ${ }^{15}$

- Finally, contributions for vocational training can be established to other beneficiary groups in the General

14 Today, the following percentages are much stratified according to the size of their workforce: $50 \%$ for companies with 250 or more workers; $60 \%$ for those with 50-249 workers; $75 \%$ for those with between $10-49$ and $100 \%$ of the quota for $6-9$. Companies with $1-5$ workers have a credit of $€ 420$ per year. In case of installation of new companies or opening of new work centers, the company will have $€ 65$ for each worker that it incorporates. Individual training permits are financed from an additional credit.

15 For example, the Marine Social Institute annually approves a training plan to contribute to the training and promotion of sea workers and raise their level of qualification and professional competence. This training plan in 2019 is co-financed by the European Social Fund, within the framework of the "Employment, training and education" operational program, in the 2014-2020 period [33].
State Budget Law of each year. There are some alternatives such as enabling training (supply and demand) to be programmed by companies for their workers and training permits. It would be done via bonus in business contributions or via subsidies.

\subsubsection{Employment incentives}

The Spanish Act 3/2012 granted to the companies that, at the end of the initial or extended duration of training and learning contracts, transformed them into indefinite contracts - whatever the date of their conclusion, a reduction in the business quota to the Social Security of 1,500 €/year for 3 years. In the case of women, this reduction was $1,800 € /$ year. The Spanish Act 43/2006 included bonuses for the maintenance of employment and equal opportunities on the Social Security business quota.

To avoid the loss of jobs as a result of the robotization process, one may take a look to the current design of other inspirational incentives: workers who had ceased in the company because of a total or absolute permanent disability and after professional recovery benefits regain their full work capacity or continue to be affected by a partial disability and return to work (with a 50\% reduction in the Social Security employer's share corresponding to common contingencies); or the incentive to change the job or function of certain workers, due to pregnancy, risk during breastfeeding or occupational diseases (with a 50\% discount on the business quota for common contingencies).

To address the risks that robotization entails, if the foreseeable number of layoffs on the occasion of the use of robots is reduced, some compensation could be accommodated. This happens currently with the incentive to reduce workplace accidents, which is established on occupational accident rates at $5 \%$ or $10 \%$. However, the General Treasury of the Social Security pays it from the Professional Contingency Fund.

\section{Conclusion}

After reviewing the trends in the Spanish legal system in recent years, in line with the priorities shared with the EU and the OECD guidelines, we have noticed that some of the current measures could be adapted to propose future solutions to the new challenges that robotization poses for the sustainability of the Social Security systems.

The analysis of other national regulatory frameworks should be carried out to better define the basic features of some common incentives within the EU to be adopted in a 
justified manner (proportional to the risks in each state) subject to control.

The European Parliament in its Resolution of February 12, 2019, on a comprehensive European industrial policy on artificial intelligence and robotics has explicitly stated that Social Security schemes should be redesigned to help workers to adapt to the new demands to ensure that the robotization gains are broadly shared. ${ }^{16}$

This contribution has just aimed to open the discussion about some possibilities on rethinking how the Social Security systems could quickly react to provide the needed protection for current and future generations, without harming competitiveness and productivity of the European companies. Efforts in this field are needed. ${ }^{17}$ This modest path could flourish by sharing this specific knowledge, and, as a consequence, similar measures could be agreed by many states along the EU territory, with the legal or even economic support of the EU institutions.

Funding: European Union's Horizon 2020 research and innovation programme, Grant agreement No. 780073.

\section{References}

[1] European Commission, "Digital Agenda: Commission and European industry commit to bigger and better robotics sector," European Commission Press Release, September 18, 2012. [Online], Available: https://europa.eu/rapid/pressrelease_IP-12-978_es.htm [Accessed May 24, 2020].

[2] N. Nevejans, "European civil law rules in robotics, study for the juri committee," Policy Department Citizens' Rights and Constitutional Affairs European Parliament, 2016. [Online]. Available: http://www.europarl.europa.eu/RegData/etudes/ STUD/2016/571379/IPOL_STU(2016)571379_EN.pdf [Accessed May 24, 2020].

[3] INBOTS, Interactive Robotics Documentary Film. [Online]. INBOTS CSA: G.A. No 780073, 2020. https://www.youtube.

16 " 5 . Notes that the current industrial landscape there is a delicate balance between the owners and the workers; considers that advances in implementing $\mathrm{AI}$ in industry should be made with broad consultation of social partners, as the potential shift in the number of people working in the industry requires proactive policies to help workers adapt to the new demands and to ensure that the gains are broadly shared; and notes that this requires rethinking and redesigning labor market policies, Social Security schemes and taxation [34].”

17 The INBOTS project will deliver to the European Commission the White Paper for the Regulation of Interactive Robotics in the EU. We will consider the replies to this survey (where the Social Security sustainability issue is included):

http://inbots.eu/inbots-experts-community/legal-ethics-socio-economicsaspects/else-robotics/

We would appreciate your feedback. Thank you.
com/watch?v=h0QjNC8XQ1U\&feature=youtu.be [Accessed: May 24, 2020].

[4] European Commission, "Digital agenda: Europeans welcome use of robots in an increasingly complex world," European Commission MEMO/12/667, September 14, 2012. [Online]. Available: https://ec.europa.eu/commission/presscorner/ detail/en/MEMO_12_667 [Accessed: May 24, 2020].

[5] International Federation of Robotics, "World Robotics 2019 Industrial Robots," International Federation of Robotics, p. 13, 2018. [Online]. Available: https://ifr.org/downloads/ press2018/Executive\%20Summary\%20WR\%202019\% 20Industrial\%20Robots.pdf [Accessed: May 24, 2020].

[6] S. Wyatt (IFR Vice President), "Positive Medium-Term Growth Expectations," IFR Press Conference, Sept. 18, 2019. [Online]. Available: https://ifr.org/downloads/press2018/IFR\% 20World\%20Robotics\%20Presentation\%20-\%2018\%20Sept \%202019.pdf [Accessed: May 24, 2020].

[7] International Federation of Robotics, "World Robotics 2019 Service Robots," International Federation of Robotics, pp.

11-12, 2018. [Online]. Available: https://ifr.org/downloads/ press2018/Executive_Summary_WR_Service_Robots_2019. pdf [Accessed: May 24, 2020].

[8] C. Müller (IFR Director Statistical Department), "Domestic Service Robot; Professional Service Robots support our Workers”, IFR Press Conference, Sept. 18, 2019. [Online]. Available: https://ifr.org/downloads/press2018/IFR\% 20World\%20Robotics\%20Presentation\%20-\%2018\%20Sept \%202019.pdf [Accessed: May 24, 2020].

[9] M. A. Grau Ruiz, J. J. Hinojosa Torralvo, E. Fosch-Villaronga, V. Müller, M. Kritikos, J. Chaves Chaparro, et al., "Tools for Inclusive Robotics: Ethics, RRI, Taxation \& Social Dialogue,” European Robotics Forum - WP2 INBOTS Workshop, Eprint UCM, March 5, 2020. [Online]. Available: https://eprints.ucm. es/59990/ [Accessed: May 24, 2020].

[10] M. A. Grau Ruiz, "Tributación y robótica responsable para una economía digital sostenible," in Tributación de la economía digital, M. F. Braccia, Ed., Thomson Reuters La Ley, Dir. Buenos Aires, 2019, pp. 655-668.

[11] International Labour Organization, "Future of Work - Major trends: The deployment of industrial robots is rapidly intensifying, with the potential to change production processes worldwide," International Labour Organization, May 1, 2017. [Online]. Available: https://www.ilo.org/global/topics/ future-of-work/trends/WCMS_555548/lang-en/index.htm [Accessed: May 24, 2020].

[12] OECD, "Skills Strategy. Informe de Diagnóstico, Resumen España 2015,” OECD, 2015. [Online]. Available: https://www. oecd.org/skills/nationalskillsstrategies/Spain_DR_ Executive_Summary_Espagnol.pdf [Accessed: May 24, 2020].

[13] McKinsey \& Company, "Skill shift: Automation and the future of the workforce," McKinsey Global Institute Discussion Paper, May 23, 2018. [Online]. Available: https://www. mckinsey.com/featured-insights/future-of-work/skill-shiftautomation-and-the-future-of-the-workforce\# [Accessed: May 24, 2020].

[14] J. I. López Sánchez, M. A. Grau Ruiz, and M. Y. Sánchez-Urán Azaña, "The impact of robotics and computerization on the labour market: Inclusive insight from a Law and Economics perspective," Revista de Derecho Digital e Innovación, vol. 1, no. 3, 2019. 
[15] R. Alós, "El empleo en España en un horizonte 2025," Economía digital y Políticas de Empleo, pp. 13-50, June 2019 [Online]. Available: https://ddd.uab.cat/pub/caplli/2019/ 205105/205105_Alos_El_empleo_en_Espana_en_un_ horizonte_2025_def.pdf [Accessed: May 24, 2020].

[16] European Commission, "EU social security coordination," European Commission Employment, Social Affairs and Inclusion. [Online]. Available: https://ec.europa.eu/social/ main.jsp?catld=849 [Accessed: May 24, 2020].

[17] INBOTS WP2, "Inbots White Paper on Interactive Robotics Legal, Ethics \& Socioeconomic Aspects," INBOTS, July 8, 2019 [Online]. Available: http://inbots.eu/wp-content/uploads/ 2019/07/Attachment_0-1.pdf [Accessed: May 24, 2020].

[18] M. Y. Sánchez-Urán Azaña and M. A. Grau Ruiz, "The impact of robotics, especially inclusive robotics, at work: legal-labor and fiscal aspects," Aranzadi Journal of Law and New Technologies, vol. 17, no. 50, pp. 1-19, 2019.

[19] High-Level Expert Group on the Impact of the Digital Transformation on EU Labour Markets, "Final Report," European Commission, pp. 43-44, April 8, 2019. [Online]. Available: https://ec.europa.eu/digital-single-market/en/ news/final-report-high-level-expert-group-impact-digitaltransformation-eu-labour-markets [Accessed: May 24, 2020]

[20] E. Weber, "Setting out for Digital Social Security," International Labour Office Working Papers, no. 34, September 2018. [Online]. Available: https://www.ilo.org/ wcmsp5/groups/public/-dgreports/-inst/documents/ publication/wcms_645871.pdf [Accessed: May 24, 2020].

[21] European Commission, "Reflection Paper On Harnessing Globalisation," European Commission, 2017. [Online]. Available: https://op.europa.eu/en/publication-detail/-/ publication/cdf27647-3706-11e7-a08e-01aa75ed71a1/ language-en [Accessed: May 24, 2020].

[22] Eurofound, "European Reshoring Monitor," European Foundation for Improvement of Living and Working Conditions, 2018. [Online]. Available: https://reshoring. eurofound.europa.eu/reshoring-cases [Accessed: May 24, 2020].

[23] European Commission, "Report on Spain 2019," European Commission Working Paper, Brussels, SWD (2019) 1008 final, 27 Feb. 2019.

[24] M. Y. Sánchez-Urán Azaña, "Inclusive robotic and work: socially and legally responsible technological innovation," in Inclusive Robotics for a Better Society, J. L. Pons, Ed., Springer, New York, 2019, pp. 37-39.

[25] A. Falcón Pulido, "Taxing Robots: Clarifications on legal and economic capacity, capacity to act and representation," in Inclusive Robotics for a Better Society, J. L. Pons, Ed., Springer, New York, 2019, pp. 40-44.

[26] X. Oberson, Taxing Robots, Edward Elgar, Cheltenham, UK, 2019.

[27] J. Englisch, "Digitalisation and the future of national tax systems: taxing robots?" Social Science Research Network, Sept. 5, 2018, p. 10. [Online]. Available: https://ssrn.com/ abstract $=3244670$ [Accessed: May 24, 2020].

[28] E. Fosch and M. A. Grau Ruiz, "Expert considerations for the regulation of assistive robotics. A European robotics forum Echo," Dilemata, vol. 11, no. 30, 2019, pp. 149-169. [Online]. Available: https://www.dilemata.net/revista/index.php/ dilemata/article/view/412000296/646 [Accessed: May 24, 2020].

[29] M. A. Grau Ruiz, "El actual dilema fiscal por el impacto de la robótica: ¿Innovación o empleo?” in Tributos, servicios digitales y robótica, Thomson-Reuters Aranzadi, Cizur Menor, 2019

[30] M. A. Grau Ruiz, Sostenibilidad global y actividad financiera. Los incentivos a la participacion privada y su control, Thomson-Reuters Aranzadi, Cizur Menor, 2019.

[31] Centre for the New Economy and Society, "Insight Report: The Future of Jobs Report," World Economic Forum, 2018, pp. 12-13. [Online]. Available: http://www3.weforum.org/docs/ WEF_Future_of_Jobs_2018.pdf [Accessed: June 3, 2020].

[32] OECD, "Skills Strategy 2019. Skills to Shape a Better Future," OECD, May 22, 2019. [Online]. Available: https://www.oecd. org/publications/oecd-skills-strategy-2019-9789264313835en.htm [Accessed: May 24, 2020].

[33] Seguridad Social, "Plan de Formación 2020 - Trabajadores del Mar," Seguridad Social, 2020. [Online]. Available: http:// www.seg-social.es/wps/portal/wss/internet/Trabajadores/ TrabajadoresMar/29482/2427/50361 [Accessed: May 24, 2020].

[34] European Parliament, "Report on a comprehensive European industrial policy on artificial intelligence and robotics," European Parliament (A8-0019/2019), January 30, 2019. [Online]. Available: https://www.europarl.europa.eu/doceo/ document/A-8-2019-0019_EN.html [Accessed: May 24, 2020]. 